\title{
Attitude of Junior College Lecturers and Students towards Present Day Examination System
}

\author{
${ }^{1}$ Mrs. T.N.Rama, ${ }^{2}$ Sri. Y. Vasudhakar Reddy \\ ${ }^{I}$ Zoology faculty, A.P. Model School, Andhra Pradesh, India. \\ ${ }^{2}$ Principal, Sri Venkateswara College of Education, Chittoor, Andhra Pradesh, India.
}

\begin{abstract}
The main purpose of this study was to examine the attitude of junior college lecturers and students towards present day examination system. The present study was undertaken using the survey method. The participants of the study were 100 lecturers and 200 students of Government and private junior colleges of chittoor town, Andhra Pradesh, India in 2010 - 2011 session. They were selected by purposive sampling method. The researchers adopted standardized tool for data collection which consisted of 60 statements, with 20 positive and 40 negative statements. Data was analyzed using statistical techniques like mean, standard deviation, $t$-test (differential analysis) and spearman's product moment correlation co - efficient. The findings revealed that the entire sample of lecturers as well as students had a low significant difference in their attitudes towards present day examination system. There was negligible positive correlation between lecturers and students. Based on the findings, suggestions were made that same study may be extended to different levels of educational institutions all over the state. Other variables like locality, qualifications, origin etc. can be included and an in depth study can be carried out in this research area.
\end{abstract}

Key words: Attitude, Examination system, Standardized tool, Differential analysis,

Correlation co-efficient, In depth study, research area.

\section{Introduction}

Examinations play a vital role in the field of educational system. Examinations test the pupils power of clear thinking, quickness of mind and perseverance. Examinations play a dominating role in determining the functional content and method of instruction. Examinations help the parents to know the progress of their wards from time to time. Examinations act as incentives and stimulate the pupils to put in hard work in order to achieve success. Examinations help in measuring the efficiency of the teachers/lecturers and the schools/colleges. Examinations provide uniformity of standard. Examinations help the students to pursue higher courses and provide ample opportunities to land into a dream job.

Types of Examinations :Examinations may be classified on the basis of type of questions i.e. Essay type, short answer type and objective type.

Essay type examination : Gilbert Sax states, "Essay test is a test containing questions requiring the student to respond in writing. Essay tests emphasize recall rather than recognition of the correct alternative. Essay tests may require relatively brief responses or extended responses". Weidemann observes that an essay type question may use the following eleven words, signifying the simple to higher mental processes - what, who, when, which and where; list, outline, describe, contrast, compare, explain, discuss, develop, summarize and evaluate. W.S. Monroe and R.E. Carter lists the following types of essay questions - analysis, application of laws, principles, rules to new situations; cause or effect, classification, comparison of two ideas or things in general, comparison of two things on a single basis, criticism as to the adequacy, correctness or relevance of a statement, decisions for and against, explanation of the use or exact meaning of some word, phrase or statement; evaluation recallbasis given.

Short answer type examination : In a simple language it may be stated that a short answer type test is between an essay type test and an objective test. According to Anthony J. Nitku, "Short answer items require the examinee to respond to the item with a word, short phrase, number or a symbol". Norman E. Granland observes, " the short answer test is an objective test in which each item is in the form of a direct question, a stimulus word or phrase, a specific direction, a specific problem or an incomplete statement or question. The response must be supplied by the examinee rather than merely being identified from a list of suggested answers supplied by the teacher.

New type or Objective tests : The traditional system of examination or the essay type of examination has come under heavy five. Students denounce it because of its heavy strain, the parents criticize it because of its injurious 
effect on the physical and mental health of the children, the teachers complain because of its harmful effect on school work. To mitigate some of the evils of the essay type examinations, objective tests seem to be very useful. Objective tests are of a large variety. However, only seven or eight types of objective tests are commonly used. R.L Ebel and D.A. Frisbie, defines an objective test as "one that can be provided with a simple predetermined test of correct answers so that objective opinion or judgment in the scoring procedure is eliminated.

Evaluation : Evaluation is a comprehensive and continuous process which covers every aspect of an individual's achievement in the educative process. It is an integral part of education in which students and teachers are partners. It signifies a wider process of judging students progress in various aspects. Evaluation is a qualitative judgment of an individual's performance. Evaluation includes academic and non-academic subjects.

Measurement : Measurement is a procedure for assigning numbers to specified attributes or characteristics of persons in a manner that maintains the real world relationship among persons with regard to what is being measured. Measurement is a quantitative determination of an individual's performance, which helps in evaluation.

Assessment : Assessment is the process by which one attempts to measure the quality of learning and teaching using various assessment techniques such as assignments, projects and seminars.

Test : Test is the presentation of standard set of questions to be answered. As a result of a person's answers to such a series of questions, we obtain a measure of a characteristic of that person.

Ancient examination system : In Ancient India, the vedic texts were often the subjects of study and examinations in their recitation were the normal practice. The examinee making a single mistake or two mistakes in the recitation was classified as a pupil of one error or two errors and in this way grading went upto 12 lapses. The stress was on memorization, an inevitably knowledge had to pass from man to man largely through oral instruction. With the advent of the British rule though there was a specific shift in the educational system, the stress on memory continued. Education was mainly for recruitment to services and depended upon the results of examination in terms of pass or fail. It was easier to measure achievement in the olden days as the number was small and the prestige of the institution or the teacher was sufficient to guarantee that the achievement was of a high order and tests used were highly reliable.

Present examination system : Now-a-days, we are dealing with the vast numbers and we cannot depend upon the reputation of either institution or the lecturer. There are both internal and external examinations in India. Internal examinations are conducted by colleges. External examinations are held at the end of the year by intermediate board of education. The main purpose of external examinations is certification which enables students either to go the university or get some employment. Both the internal and the external examinations in this country are more or less modeled on similar lines and they follow the same general pattern. Both are intended to test mainly the academic attainments of a pupil. These do not test in detail the all round development of pupils. Thus the problem of tests used and the large number of persons to be tested have complicated the process of present examination system.

\section{Drawbacks of the present examination system :}

- Lack of definite aim.

- Element of chance.

- Lowering of educational standard.

- Lowering of moral standard.

- Ignoring qualities of character like originality, initiative, truthfulness, honesty, sociability.

- Element of subjectivity.

- Heavy mental strain.

- Developing frustration due to failures.

- Certificate inflation.

- Dehumanizing effect.

- Promoting supremacy of text books.

- Disappearance of the real educational values. 
Different types of examination systems : External examination system, internal examination system for promotion purpose, marks and grades, semester examination system, credit system, internal assessment, nondetention system.

\section{STATEMENT OF THE PROBLEM AND PURPOSE OF THE STUDY.}

The examinations have an important role in education. It is necessary for parents and lecturers to know from time to time how the students are progressing and what their attainments are at any particular stage. The present examination system tests only memory and it does not measure the all round development of the students. It was thought that it is highly unreliable and adequate, and has a demoralizing effort on lecturers and students resulting in the loss of national character and ideals.

It was believed that the system of examination has corroded the whole junior college atmosphere and resulted in the development of undesirable attitudes among the lecturers and students to find out whether their belief is true and if it is true what steps have to be taken for changing their attitudes, which are essential for good evaluation. The actual study is intended to find out the attitude of lecturers and students of junior colleges towards the present day examination system and study the influence of certain variables like gender, experience, management and achievement on their attitudes.

In this study, survey method was adopted.

\section{Location and sample of the study :}

The research was conducted on lecturers and students of Government and Private junior colleges in Chittoor town, Andhra Pradesh, India. The participants were selected by purposive sampling method. A random sample of 100 lecturers and 200 students of Government and Private junior colleges in Chittoor town, Andhra Pradesh were choosen for the study.

TABLE -I Distribution of the total sample and its sub samples

\begin{tabular}{|c|c|c|c|}
\hline Sl. No & \multicolumn{2}{|c|}{ Categories } & Number \\
\hline 1. & \multicolumn{2}{|l|}{ Entire Sample } & 300 \\
\hline \multirow[b]{2}{*}{2.} & \multirow[b]{2}{*}{ Designation } & Lecturers & 100 \\
\hline & & $\begin{array}{l}\text { Students } \\
\text { (Jr. Inter - 100 } \\
\text { Sr. Inter - 100) }\end{array}$ & 200 \\
\hline \multirow{2}{*}{3.} & \multirow{2}{*}{ Gender (Lecturers) } & Male & 51 \\
\hline & & Female & 49 \\
\hline \multirow{2}{*}{4.} & \multirow{2}{*}{ Gender (Students) } & Male & 124 \\
\hline & & Female & 76 \\
\hline \multirow{2}{*}{5.} & \multirow{2}{*}{ Experience (Lecturers) } & Above 5 yrs & 62 \\
\hline & & Below 5 yrs & 38 \\
\hline \multirow{2}{*}{6.} & \multirow{2}{*}{ Achievement (Students) } & Below $50 \%$ & 43 \\
\hline & & Above $50 \%$ & 157 \\
\hline \multirow{2}{*}{7.} & \multirow{2}{*}{ Management (Lecturers) } & Private & 62 \\
\hline & & Government & 38 \\
\hline \multirow{2}{*}{8.} & \multirow{2}{*}{ Management (Students) } & Private & 131 \\
\hline & & Government & 69 \\
\hline
\end{tabular}


FIG. 1

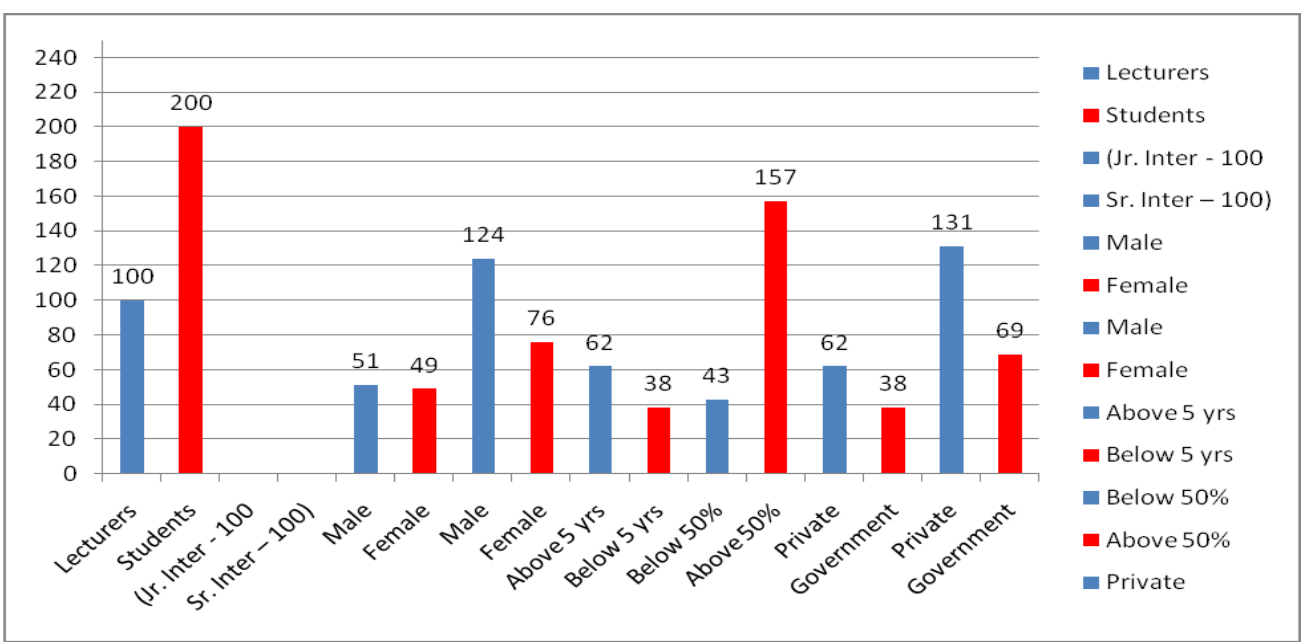

\section{Tool used for data collection :}

The researchers adopted standardized tool prepared by Dr. P. Vimala Devi and P. Silpa for collecting the data. The tool consisted of 60 statements, with 20 positive and 40 negative statements. The tool consisted of statements with regard to different aspects of present day examination system like content, purpose of examinations, student aspects, teacher aspects, society, problems, time adequacy, examination system, opportunities, standards.

The scoring was done with the help of Likert's five point scale. The weightings were Strongly Agree $(\mathrm{SA})=5$, Agree $(\mathrm{A})=4$, Undecided $(\mathrm{U})=3$, Disagree $(\mathrm{D})=2$, Strongly Disagree $(\mathrm{SD})=1$ for positive statements and Strongly Agree $(\mathrm{SA})=1$, Agree $(\mathrm{A})=2$, Undecided $(\mathrm{U})=3$, Disagree $(\mathrm{D})=4$, Strongly Disagree $(\mathrm{SD})=5$ for negative statements. An individual's score is the sum of all the scores for the 60 statements.

\section{Method of data collection :}

The personal data sheet and the openionaire to measure the attitude towards present day examination system was administered to lecturers and students. Before the administration of the tool, the principals of the colleges were requested to give permission, for the collection of data. The copies of tool was administered to lecturers and students. The researchers first explained the importance of investigation to the lecturers and students. Before giving the openionnaire to the examinee, certain instructions were given for getting appropriate responses.

\section{Data analysis :}

Descriptive statistics ( Mean and Standard deviation ) of the attitude scores of entire sample of lecturers and students and their sub-samples were calculated.

The null hypothesis for sub-samples was tested by employing ' $t$ ' test at $5 \%$ level of significance using the following formula

$$
t=\frac{\overline{x_{1}}-\overline{x_{2}}}{\sqrt{\frac{\sigma 1^{2}}{n 1}+\frac{\sigma 2^{2}}{n 2}}} N t_{\left(n_{1}+n_{2}-1\right)} \text { at } 5 \% \text { level of significance }
$$

Spearman's product moment correlation co-efficient was used to analyze the data and to find out the relationship between attitudes of lecturers and students towards present day examination system. The formula is as follows.

$$
r=\frac{\frac{1}{n} \varepsilon x y-\bar{x} \bar{y}}{\sqrt{\frac{1}{n} \varepsilon x^{2}-(\bar{x})^{2}} \sqrt{\frac{1}{n} \varepsilon y^{2}-(\bar{y})^{2}}}
$$




\section{Results}

The results were presented in line with research statements and hypothesis.

TABLE - II

\begin{tabular}{|c|c|c|}
\hline Entire Sample & Mean & S.D \\
\hline Lecturers & 179.24 & 20.06 \\
\hline Students & 176.73 & 18.975 \\
\hline
\end{tabular}

FIG. 2: MEAN OVERALL ATTITUDE SCORES OF LECTURERS AND STUDENTS

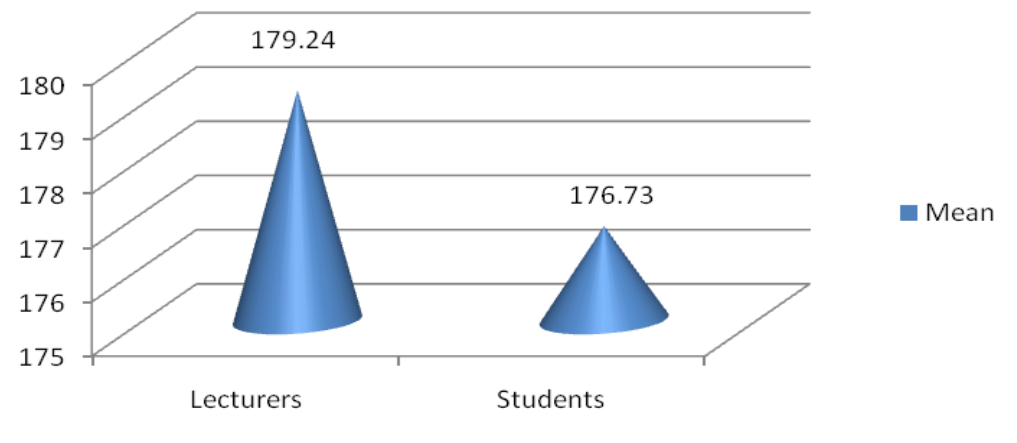

The minimum possible score for attitude scale is 60 and the maximum score possible for attitude scale is 300 . The mid value is $60+300 / 2=360 / 2=180$ is the neutral point.

Hence any score above 180 was considered as positive attitude and below it was considered as negative attitude.

Since the calculated mean values for entire sample of lecturers (179.24) and students (176.73) were less than 180 and the calculated mean scores of sub-samples ranged from 173.77 to 186.90 for lecturers and 174.80 to 179.43 for students which were less than 180 , it was predicted that lecturers and students were having negative attitude towards present day examination system.

Similarly, the calculated value of SD is 20.06 for a sample of 100 lecturers and 18.975 for a sample of 200 students indicated that the lecturers as well as students differ significantly in their attitudes towards present day examination system.

The table value ' $t$ ' at $5 \%$ level of significance is 1.96 . The calculated ' $t$ ' value for all the sub-samples were shown in the following table.

TABLE - III

\begin{tabular}{|c|c|c|c|c|}
\hline Sl. No & \multicolumn{2}{|c|}{ Sub Samples } & $\mathrm{t}$ - value & Null Hypothesis $\left(\mathrm{H}_{0}\right)$ \\
\hline \multirow{2}{*}{1.} & \multirow{2}{*}{ Gender (Lecturers) } & Male & \multirow{2}{*}{1.16} & \multirow{2}{*}{ Accepted } \\
\hline & & Female & & \\
\hline \multirow{2}{*}{2.} & \multirow{2}{*}{ Experience (Lecturers) } & Above 5 yrs & \multirow{2}{*}{3.295} & \multirow{2}{*}{ Rejected } \\
\hline & & Below 5 yrs & & \\
\hline \multirow{2}{*}{3.} & \multirow{2}{*}{ Management (Lecturers) } & Private & \multirow{2}{*}{2.385} & \multirow{2}{*}{ Rejected } \\
\hline & & Government & & \\
\hline \multirow{2}{*}{4.} & \multirow{2}{*}{$\begin{array}{l}\text { Gender } \\
\text { (Students) }\end{array}$} & Male & \multirow{2}{*}{1.556} & \multirow{2}{*}{ Accepted } \\
\hline & & Female & & \\
\hline \multirow{2}{*}{5.} & \multirow{2}{*}{$\begin{array}{l}\text { Achievements } \\
\text { (Students) }\end{array}$} & Below $50 \%$ & \multirow{2}{*}{0.220} & \multirow{2}{*}{ Accepted } \\
\hline & & Above $50 \%$ & & \\
\hline \multirow{2}{*}{6.} & \multirow{2}{*}{ Management (Students) } & Private & \multirow{2}{*}{1.181} & \multirow{2}{*}{ Accepted } \\
\hline & & Government & & \\
\hline
\end{tabular}

A conclusion was made that sub-samples had a low significant difference in their attitudes towards present day examination system. 
The correlation co-efficient $(\mathrm{r}$ ) value for lecturers and students was found to be 0.087537

It means positive negligible correlation was present. Hence, it was concluded that there was low significant difference in the attitude of lecturers and students of junior colleges towards present day examination system.

\section{Discussion}

From this study and the findings, it was found that the lecturers and students were having significant difference in their attitudes towards present day examination system.

\section{Suggestions}

- Significant differences were there in the attitudes of lecturers and students towards present day examination system. Hence, it was advised that certain reforms had to be done.

- It was suggested that examination should test the real knowledge of students, by giving more application type questions.

- It was inferred from the study that question papers do not contain questions from all areas. Hence, it was advised that paper setters should take care and due importance should be given to each area.

- Present day examination system do not test the creativity of the pupils. To rectify this, question papers should be in such a way that they develop creative ability in students.

- Lecturers give much importance in completing the syllabus rather than conceptual clarity. Hence, orientation should be given to lecturers to make them understand that conceptual clarity is more important.

- Element of subjectivity and repeated questions over the years in the examinations should be reduced.

- Essay type examinations should be minimized by introducing objective type tests and also by changing the type of questions.

- Written examinations help in knowing the abilities of learners. So, there is a need for some kind of monitoring of learning during the course of instruction.

- Examination steps are a very important factor influencing examination performance. Students should be motivated to learn their lessons daily, so that there is less tension during examination time.

- Utmost care must be taken that question papers contain questions from all areas.

- In examinations, generally it is observed that if open choice is given, students prefer to write answers which take less time. So it is advised to frame all questions of equal difficulty level and also taking equal time. It is better to give internal choice questions rather than open choice questions.

\section{Recommendations}

- Examinations should form an integral part of learning.

- The administration and organization of examinations should be improved.

- Examinations should be conducted in such a way that they become effective instruments of education. They should serve as stimulus to learn new facts, gain new experiences, discover weak points and estimate progress.

- Standard of marking should be prescribed so as to minimize the variability in marking.

- The paper setters and examiners for external examinations should be drawn from the lecturers who actually teach subject in schools.

- Lecturers should be given special training in setting question papers and valuing answer scripts by conducting seminars and workshops.

- Any change in the examination system should be made only after careful experimentation and in consultation with the lecturers.

- The educational authorities should give considerable importance to the attitudes of lecturers towards educational controversies. The educational department should consider the opinion or the view of lecturers before bringing about any radical change in its educational system.

\section{References}

[1]. Bhat, R.N. Gunasekarn, K. Shanmugam, M. (1978) Study related to a comparative study of the grade table and direct grade methods, Journals on Examination Reform Unit @ Madras.

[2]. Bhola (1978), Study related to the reliability and validity of question items, III Survey of Educational Research.

[3]. Bose et al., (1967), Study related to the framing a good questions, III Survey of Educational Research.

[4]. Chatterji. S., Mukharjee. M. Study related to the factorial composition of school examination marks, psychometric research and service unit, III Survey of Educational Research.

[5]. Chauhan (1967), Study related to the university examinations system, III Survey at Educational Research.

[6]. Dr. Mangal. S.K. January 2006, Make a case for employing teacher evaluation by students, January Examination Article.

[7]. Dr. Marlow Ediger, the principle and evaluation of student achievement, Article - Jan. 2000. 
[8]. Dr. Nirmala Jyothi, M. Dr. Sudhakar Reddy, Y. August 1996, Study related to impact of the non-detention system on the achievement of X class students, Journal of Examination System and Research.

[9]. Emerging Trends in Educational Evaluation, CPS Chauhar.

[10]. GCPI 1971, An experiment in reforming the examination system, Studies on Experimental Education@ Allahabad.

[11]. GC PI 1981, A study of the factors responsible for good examination results, Studies on Experimental Education.

[12]. Guna Sekhar, k. Jayanthi, P. (1976-77), A study of the continuous internal assessment and the university examination marks of the under graduate, III Survey of Educational Research.

[13]. K.P.Anil Kumar, Jan.2006, Study related to student evaluation, vision and perspectives. Journal of Extension and Research, Volume VIII No. 1 \& 2.

[14]. Lele et al., (1963) Study related to the essay type examinations III Survey of Eduational Research.

[15]. L.M.Tiwari , (1975), Evaluation and its problem in upper-primary schools. III Survey of the Educational Research.

[16]. Mascarenhas M.J. (1977), a critical survey of examination reforms undertaken by the Maharashtra state board of secondary education with special reference to question papers in higher level. III Survey of the Educational Research.

[17]. Misra V.S. (1970), Study related to the discrimination values of essay type questions, IV Survey of Educational Research

[18]. Misra V.S. (1972), A follow up study of examination reforms in Gouhati University Journal of Examination.

[19]. Mr. Kulkarni P.R. (1960) Lessing the burden of examination article.

[20]. Mr. Mithelesh Kanthi 1967, Examination reform and teacher Examination Article.

[21]. National Eduational Policy - 1986, Study related to examination system.

[22]. N.L.M.Jayanti, T.Padmanaban, Oct. 2008, Study related to "test anxiety of higher secondary students". EDUTRACKS - Oct. 2008, Vol. VIII, No. 2.

[23]. Rao (1968), Study related to the system of examination III Survey of Educational Research.

[24]. Reddy A.V.R. (1979), An attitude of teachers of two institutions towards internal assessment, III Survey of Educational Research

[25]. S. Thangasamy, Jan. 2004, Study related to causes of grade repetition in primary education, Journal of Extension and Research Volume Vol. No. 1 \& 2 .

[26]. S.K. Sinha 1977, "study related to attitudes of students towards the present system of examination", IV Survey of Educational Research.

[27]. Taylor H. J. Tluanga L. N., Mishra V. S. (1966) study related to the inconstant examiner IV Survey of Educational Research.

[28]. Varma I. K. (1981), A critical appraisal of some innovations for the improvement of examinations, Journal of Experiments in Education.

[29]. Venkubai. J 1965, A study of the internal assessment use and misuse, directorate of higher education, III Survey of the Educational Research.

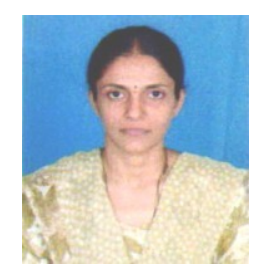

Mrs. T.N.Rama M.Sc.,M.Phil., M.Ed. is currently working as Zoology Faculty in A.P. Model School, Government of Andhra Pradesh, India. She pursued B.Ed. and M.Ed. in Sri Venkateswara College of Education, Chittoor, Andhra Pradesh, India. Her Research area is related to present day examination system.

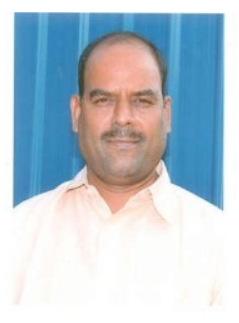

Sri.Y.Vasudhakar Reddy M.A., M.Phil., M.Ed., Ph.D. is currently working as Principal in Sri Venkateswara College of Education, Chittoor, Andhra Pradesh, India. His Research area is related to present day examination system. 